\title{
Sonographic and Doppler predictors of malignancy in ovarian lesions
}

\author{
Lamiaa M. R. Khalaf ${ }^{1 *}$, Hagar H. M. Desoky ${ }^{1}$, Gehan S. Seifeldein², Asmaa Salah³ ${ }^{3}$ Maged Abdelfattah Amine ${ }^{4}$ and
} Marwa T. Hussien ${ }^{5}$

\begin{abstract}
Background: To determine the best sonographic (US) and/or Doppler features that the radiologist can use as predictors or risk factors for ovarian malignancy

Results: Among the examined 156 ovarian lesions, there were 53 malignant and 103 benign lesions. Most of the malignant ovarian lesions were noted in older age than in benign lesions $p<0.001$. Majority of the malignant lesions had non-hyperechoic solid component (92.5\%); it had the highest sensitivity of $92.5 \%$, specificity of $97 \%$, accuracy of $94.8 \%$, positive predictive value of $94 \%$, negative predictive value of $96 \%$, and AUC of 0.94 in discrimination between benign and malignant ovarian lesions. The presence of papillary projection, the absence of wall definitions and thick wall, and thick septation were noted in $83 \%, 81 \%$, and $53.8 \%$ of the malignant ovarian lesions respectively. Color flow Doppler shows neovascularity in $88.7 \%$ of the malignant lesions, $73.6 \%$ of them has central blood flow. The multivariate regression analysis revealed that the presence of non-hyperechoic solid component, new vascularity with central location of the blood flow, papillary projection, thick septa, and old age were the most significant parameters in predicting ovarian cancer in decreasing order of frequency according to their odds ratio $(19.45,7.55,4.56,3.45$, and 1.45 , respectively).
\end{abstract}

Conclusions: The non-hyperechoic solid component, new vascularity with central location of the blood flow, papillary projection, and thick septa were the most significant and consistent US and Doppler predictors of ovarian malignancy in addition to one clinical feature which is the old age $\geq 52$ years.

Keywords: Ovarian mass, Gray-scale US, Doppler, Malignancy, Predictors

\section{Background}

Ovarian cancer is the fifth most common cancer death among women [1], and the second most common gynecologic malignancy [2]. Unfortunately, most women are diagnosed in late stages that have a poor survival rate [3], while only $20 \%$ are diagnosed at early stages, in which the 5-year survival rate exceeds 90\% [4]. Preoperative characterization of the ovarian masses poses a special diagnostic challenge, as it has a great impact on the patient's prognosis, survival rate, and the treatment strategies [5]. Serum CA-125 levels and pelvic

\footnotetext{
* Correspondence: lamiaa_refaat@yahoo.com

'Diagnostic Radiology Department, South Egypt Cancer Institute, Assiut University, 8 El Mesak Street Branch of King Seti, Assuit 71111, Egypt Full list of author information is available at the end of the article
}

examination have failed to discriminate between benign and malignant ovarian lesions, owing to their low sensitivity and high false-positive rate [6]. Gray-scale ultrasonography (US) is the modality of choice in identifying and characterizing ovarian lesions with $65-94 \%$ accuracy [7], 88-96\% sensitivity, and $65-94 \%$ specificity [8]. Various mathematical models, scoring systems, and software programs that based on sonographic findings were proposed for differentiation between benign and malignant ovarian tumors [9], but until now, there is no scoring system that has been accepted as gold standard for predicting the ovarian lesions at risk. Color and spectral Doppler are the subject of great debate about their efficacy in differentiation between benign and malignant ovarian lesions [10]. Previous studies have shown that 

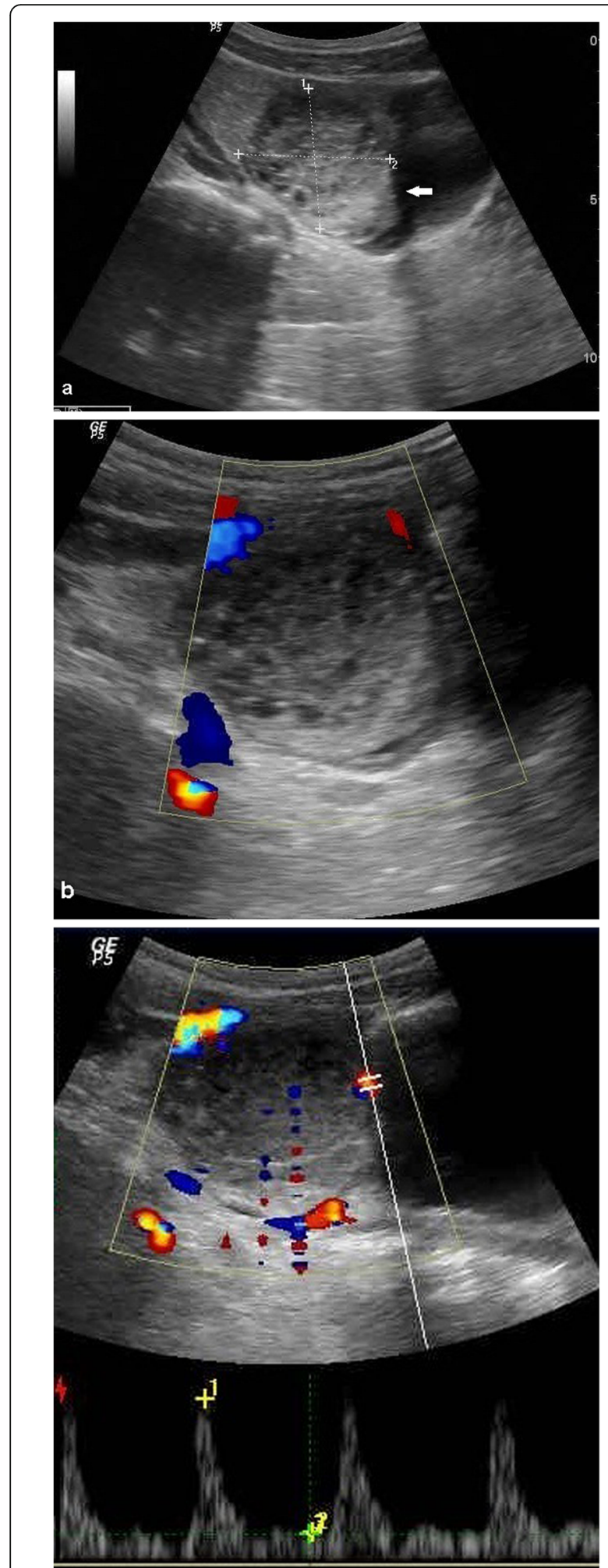

C
Fig. 1 A 27-year-old woman presented with intermittent lower abdominal pain. a Transabdominal ultrasound demonstrating a cystic lesion that has a solid-appearing area with a concave margin (arrow) due to retractile clot, and this area demonstrate a reticular lace like pattern due to fibrin strands. $\mathbf{b}$ Doppler ultrasound shows faint peripheral flow with no central flow within the lesion with spectral Doppler on the detected peripheral vessel; the RI was 0.7 and PI was 1.4. After 6 weeks of sonographic follow-up, there was a complete resolution of this lesion and it was characteristic of hemorrhagic cyst

this technique may be useful as a second step technique or when the US features are inconclusive [11], while others concluded that it adds little additional information [12].

This study aims to determine the best sonographic and/or Doppler features that the radiologist can use as predictors or risk factors for ovarian malignancy, which in turn help the radiologist to select the high risk ovarian lesions that need further investigations in a specialized center.

\section{Methods}

\section{Patients selection}

This prospective cross-sectional study was approved by our institutional review board (IRB no. 17100016). Written informed consent was obtained from each patient for participation and publication after receiving information about the details of the study. This trial was registered in the US National library of medicine with NCT03175991 number in clinical trial. The sample size was calculated using the Open Epi software program, version 23.1.

This study was carried out between March 2017 and August 2018. One hundred sixteen women were studied in our center based on suspicion of having ovarian lesion on clinical examination, accidentally discovered ovarian lesion on US examination or computed tomography, or having high serum level of CA-125.

\section{Method}

After fulfilling the clinical data (including the age and menopausal status), all patient's pelvises were examined by Prosound Alpha 7 ultrasound machine (Hitachi Aloka Medical America, Inc., Germany). We used transabdominal, transvaginal, or both approaches.

\section{Gray-scale sonographic and Doppler data analysis}

Each ovarian lesion was evaluated morphologically according to the following parameters: tumor volume more or less than $10 \mathrm{~cm}^{3}$, solid component (not present, hyperechoic, non-hyperechoic), cystic component (not present, anechoic, echogenic), papillary 
projection, septal thickness (not present, thin $<3$ $\mathrm{mm}$, thick $\geq 3 \mathrm{~mm}$ ), and wall thickness (not identified, thin $<3 \mathrm{~mm}$, thick $\geq 3 \mathrm{~mm}$ ).

After morphological evaluation, color flow Doppler was activated. It was stated as having flow when the flow was central, and it was considered to have no flow when no signal could be detected or if the blood flow was peripheral. Once a central vessel was identified by the color Doppler US, the spectral Doppler parameters as resistive index (RI) and pulsatility index (PI) were automatically calculated. The lowest RI and PI were used for analysis, if there were more than one vessel within the lesion [9].

The following diagnostic algorithm was used:

Any mass has the following criteria: volume $\geq 10 \mathrm{~cm}^{3}$, non-hyperechoic solid component, papillary projection, septal thickness $\geq 3 \mathrm{~mm}$, wall thickness $\geq 3 \mathrm{~mm}$, mass with central blood flow and RI $<0.6$, and PI $<1.6$ were categorized as suspicious for malignancy [10].

The gold standard test for the benign lesions (as hemorrhagic cysts (Fig. 1)) was spontaneous resolution after 6-8 weeks of sonographic follow-up $(n=88)$. However, the gold standard test was a histopathological examination of all the malignant ovarian lesions $(n=53)$ and 15 benign ovarian lesions which have not typical signs of benignity. Tumors were classified according to the FIGO criteria [13] and staged according to WHO criteria [14].

\section{Statistical analysis}

Data was collected and analyzed using SPSS (Statistical Package for the Social Science, version 20, IBM, and Armonk, New York). Continuous data were expressed in the form of mean \pm SD or median (range), while nominal data were expressed in the form of frequency (percentage). The sensitivity, specificity, positive predictive value (PPV), negative predictive value (NPV), accuracy, positive likelihood ratio, and negative likelihood ratio for each sonographic and Doppler parameter were calculated using the ROC curve. Chi-square test was used to compare the nominal data of different groups in the study, while the student $t$ test was used to compare the mean of different two groups and ANOVA tests for more than two groups. Multivariate regression analysis for predictor of ovarian malignancy was calculated; $p$ value was significant if $<0.05$.

\section{Results}

One hundred fifty six lesions were detected in the examined 116 women, and 103 (66\%) lesions were benign and 53 (44\%) lesions were malignant. Regarding the clinical data of the examined women, most of the malignant ovarian lesions were noted in older age than in benign lesions with $<0.001 p$ value and significant odds ratio $=1.45(p=0.04)$; also, the majority of the malignant ovarian lesions were in the postmenopausal women ( $n=35,66 \%)$, while most of the benign ovarian lesions were in the premenopausal women $(n=74,71.8 \%) p<0.001$, but its odds ratio was insignificant $(1.22, p=0.4)$.
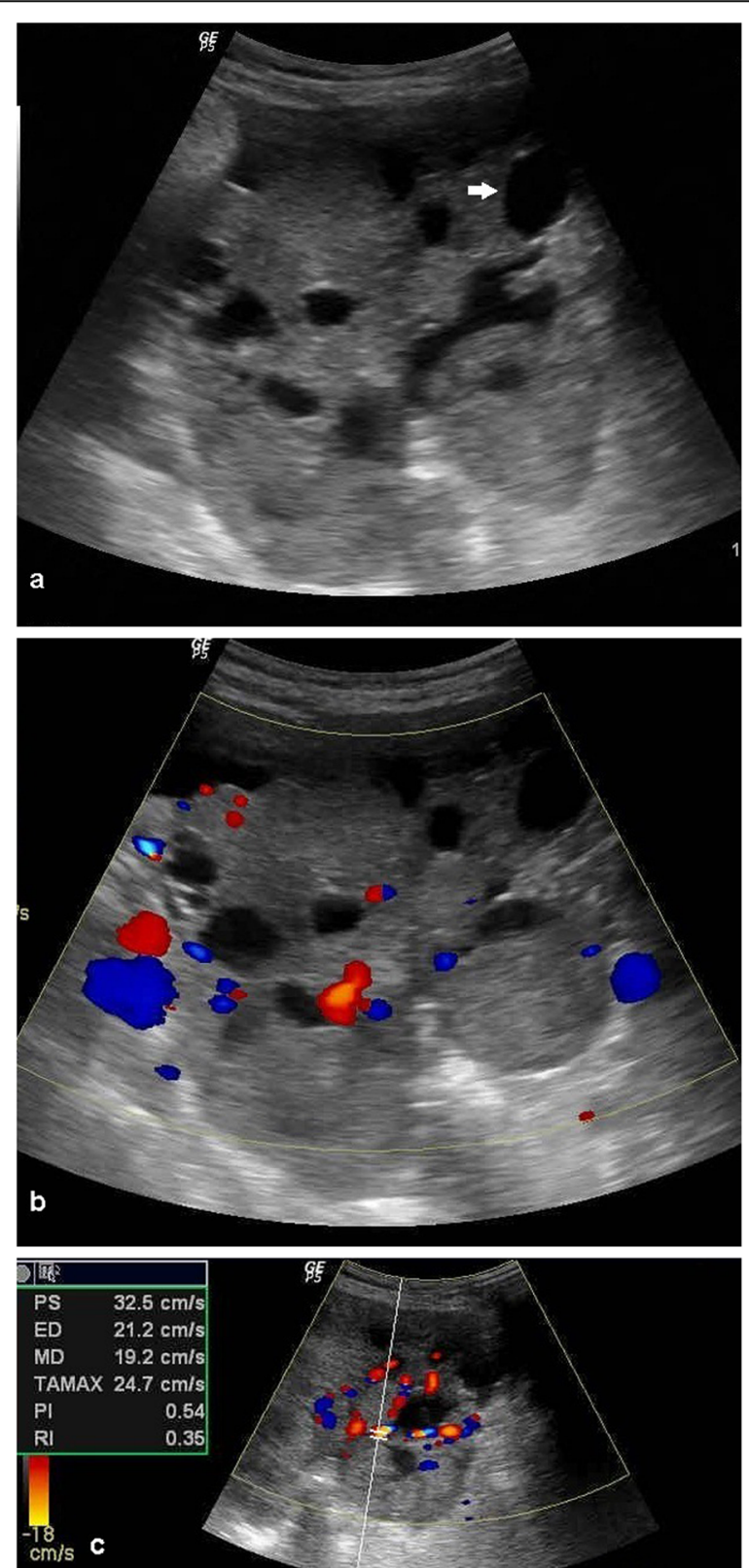

Fig. 2 A 55-year-old woman with GB adenocarcinoma on metastatic work up. a Transabdominal ultrasound shows non-hyperechoic soft tissue mass with cystic component within (white arrow). b Doppler ultrasound detects multiple central blood flow within the solid mass. c Spectral Doppler shows $0.3 \mathrm{RI}$ and $0.5 \mathrm{PI}$. The histopathological examination after true-cut needle biopsy revealed metastatic adenocarcinoma 


\section{Gray-scale US morphological feature analysis}

All US features including tumor volume, tumor component, papillary projection, septal thickness, and wall thickness had a statistically significant difference between benign and malignant ovarian lesions; the $p$ value of each of them was $<0.001$ except that of tumor volume was 0.02 . Mean tumor volume was significantly larger in malignant ovarian lesions $(890.82 \pm 123.76)$ in comparison to benign lesions (798.32 \pm 187.69$)$ with insignificant odds ratio $(0.56, p=0.06)$. The majority of the malignant lesions had non-hyperechoic solid component (92.5\%) (Fig. 2), and also it had the highest sensitivity, specificity, accuracy, PPV, NPV, and AUC in discrimination between benign and malignant ovarian lesions as demonstrated at Table 1 with 19.45 odds ratio $(p=0.01)$ in predicting ovarian cancer, while the majority of benign lesions had no solid component (92.2\%). The presence of papillary projection was noted in $83 \%$ of the malignant lesions with 4.56 odds ratio $(p=0.02)$ (Fig. 3), in contrast to $6.8 \%$ in benign lesions. Thick septation was noted in $53.8 \%$ of the malignant lesions with 3.45 odds ratio $(p=0.04)$ (Fig. 4$)$; however, the cases of benign lesions had no or thin septa (97\%). The absence of wall definitions and thick wall was present in $81 \%$ of the malignant lesions.

\section{Doppler parameter analysis}

Color Doppler shows neovascularity in $88.7 \%$ of the malignant ovarian lesions; $73.6 \%$ of them show central blood flow, in contrast to only $1.9 \%$ central flow in benign lesions (Table 2). From the logistic regression test, the new vascularity with central flow is a predictor of ovarian cancer with 7.55 odds ratio $(p=0.04)$. From

Table 1 Diagnostic performance of the gray-scale US features

\begin{tabular}{|c|c|c|c|c|}
\hline Indices & $\begin{array}{l}\text { Non-hyperechoic } \\
\text { solid component }\end{array}$ & $\begin{array}{l}\text { Cystic } \\
\text { component }\end{array}$ & $\begin{array}{l}\text { Papillary } \\
\text { projection }\end{array}$ & $\begin{array}{l}\text { Septal } \\
\text { thickness }\end{array}$ \\
\hline Sensitivity & $92.5 \%$ & $55 \%$ & $83 \%$ & $36 \%$ \\
\hline Specificity & $97 \%$ & $68 \%$ & $93.2 \%$ & $97 \%$ \\
\hline $\begin{array}{l}\text { Positive } \\
\text { predictive value }\end{array}$ & $94 \%$ & $47 \%$ & $86 \%$ & $86.4 \%$ \\
\hline $\begin{array}{l}\text { Negative } \\
\text { predictive value }\end{array}$ & $96 \%$ & $75 \%$ & $91.4 \%$ & $75 \%$ \\
\hline $\begin{array}{l}\text { Positive } \\
\text { likelihood ratio }\end{array}$ & 32 & 2 & 12 & 12 \\
\hline $\begin{array}{l}\text { Negative } \\
\text { likelihood ratio }\end{array}$ & 0.08 & 0.67 & 0.18 & 0.76 \\
\hline Accuracy & $94.8 \%$ & $62 \%$ & $88.4 \%$ & $82 \%$ \\
\hline $\begin{array}{l}\text { Are under the } \\
\text { curve }\end{array}$ & 0.94 & 0.61 & 0.88 & 0.66 \\
\hline$p$ value & $<0.001$ & 0.03 & $<0.001$ & 0.04 \\
\hline
\end{tabular}

$p$ value was significant if $<0.05$
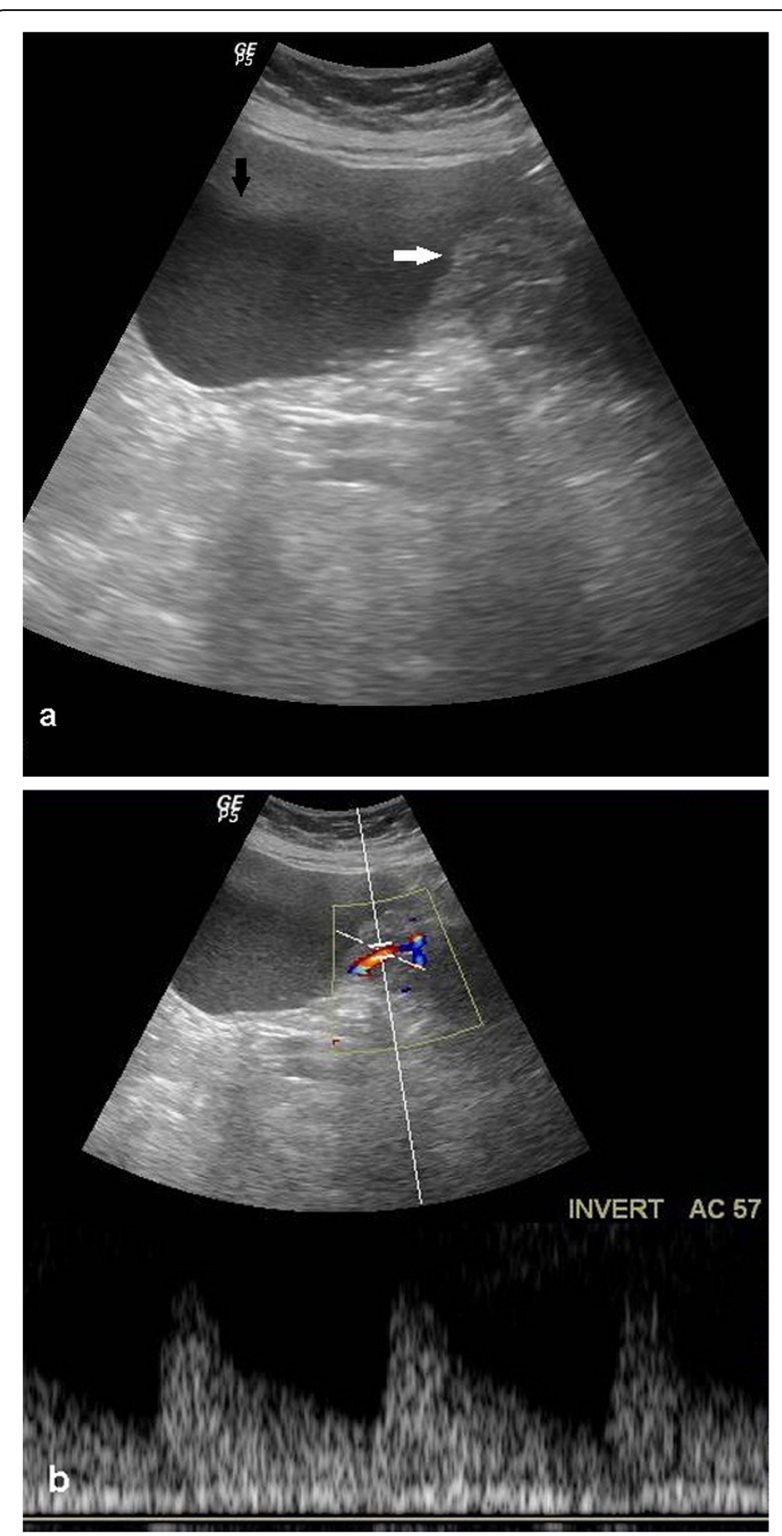

Fig. 3 A 50-year-old woman was complained of lower abdominal distension and weight loss. a Transabdominal ultrasound demonstrating a cystic lesion with turbid content (black arrow) and solid soft tissue mass at its periphery (papillary projection) (white arrow). $\mathbf{b}$ Spectral Doppler of the centrally detected blood vessel within the solid portion shows $0.4 \mathrm{RI}$ and $0.8 \mathrm{PI}$. The histopathological examination after total abdominal hysterectomy with bilateral salpingo-oophorectomy revealed adult granulosa cell tumor

Table 3, we noted that the diagnostic performance of RI $<0.6$ was higher than PI at $<1.6$ cutoff point.

\section{Discussion}

US plays an important role in the identification and characterization of ovarian lesions. Thus, several studies have been conducted in the world to evaluate the role of 

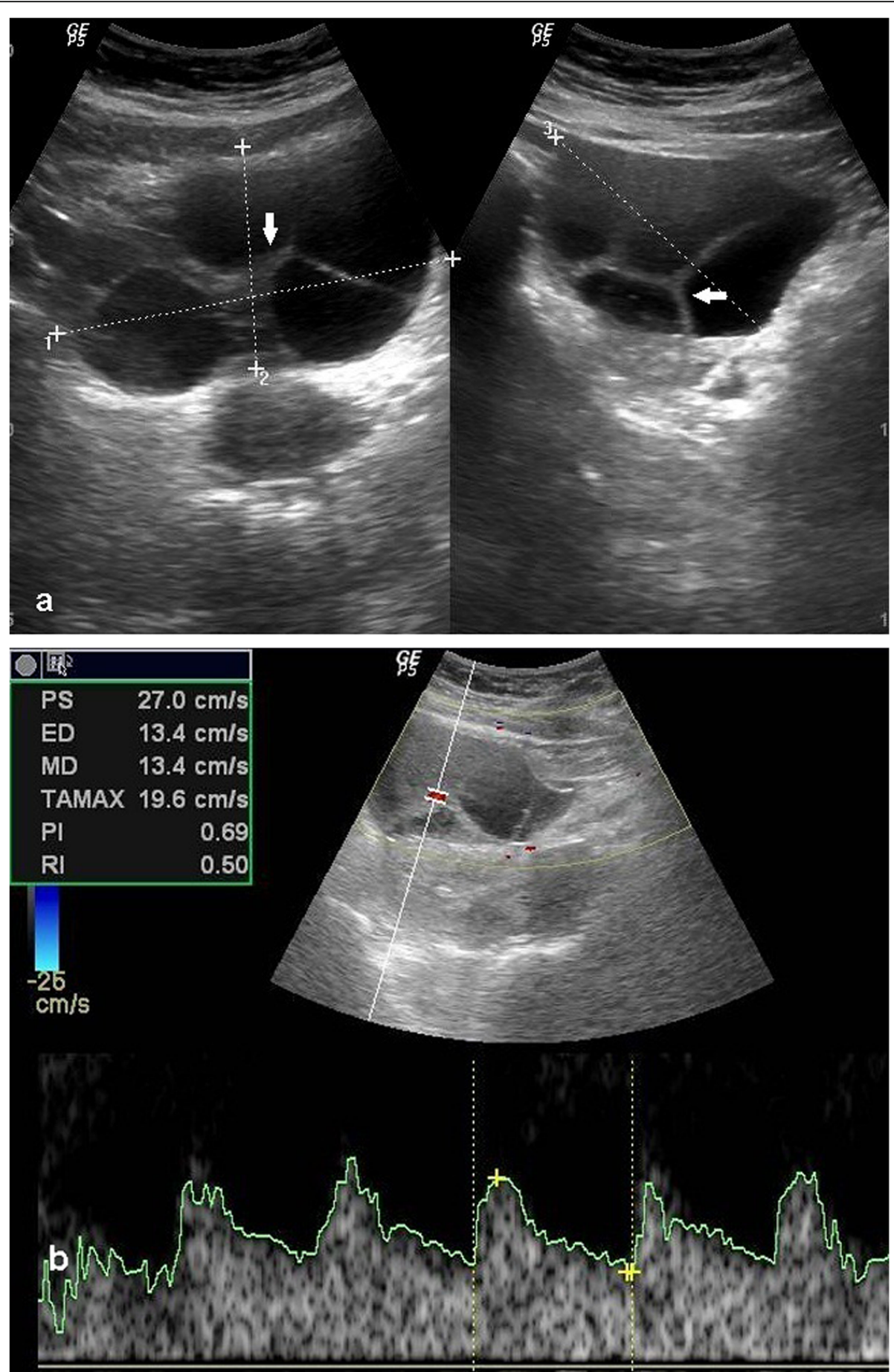

Fig. 4 A 48-year-old woman with accidentally discovered right ovarian lesion on ultrasound. a Transabdominal ultrasound shows cystic lesion with multiple thick septa (white arrow); it measures $10 \mathrm{~cm} \times 7 \mathrm{~cm} \times 6 \mathrm{~cm}$, b while spectral Doppler ultrasound detects blood flow within the central portion of the septa and shows $0.5 \mathrm{RI}$ and $0.6 \mathrm{Pl}$. The histopathological examination after laparoscopy revealed serous cystadenoma

the gray-scale and Doppler US in the characterization of benign and malignant ovarian lesions $[10,11]$, but the results have been conflicting.

We found that the age was the most important clinical risk factor for ovarian cancer as we noted from the multivariate regression test with 1.45 odds ratio, and also the risk of ovarian cancer increases in postmenopausal women than in premenopausal women, as between the 53 malignant ovarian lesions, 35 patients $(66 \%)$ were in the post menopause; however, $71.8 \%$ of the benign 
Table 2 Doppler ultrasonographic findings of the ovarian lesions

\begin{tabular}{llll}
\hline & $\begin{array}{l}\text { Benign } \\
\text { lesions (103) }\end{array}$ & $\begin{array}{l}\text { Malignant } \\
\text { lesions (53) }\end{array}$ & $p$ value \\
\hline Amount of flow & $67(65 \%)$ & $6(11.3 \%)$ & $<\mathbf{0 . 0 0 1}$ \\
$\quad$ None & $36(35 \%)$ & $8(15.1 \%)$ & \\
$\quad$ Scanty & 0 & $27(50.9 \%)$ & \\
$\quad$ Moderate & 0 & $12(22.6 \%)$ & \\
$\quad$ Abundant & & & $<\mathbf{0 . 0 0 1}$ \\
Location of the flow & $67(65 \%)$ & $6(11.3 \%)$ & \\
None & $34(34 \%)$ & $8(15.1 \%)$ & \\
Peripheral & $2(1.9 \%)$ & $39(73.6 \%)$ & \\
Central & $2.54 \pm 1.08$ & $1.6 \pm 0.51$ & $<\mathbf{0 . 0 0 1}$ \\
Pulsatility index & $0.89 \pm 0.17$ & $0.60 \pm 0.18$ & $<\mathbf{0 . 0 0 1}$ \\
Resistive index & & & \\
\hline
\end{tabular}

Data was expressed in the form of mean (SD), frequency (percentage). $p$ value was significant if $<0.05$

lesions were in the premenopausal status. These results were concordant with the results of Khurana et al. [9] who reported that $68.6 \%$ of the benign lesions were in the premenopausal women.

All the gray-scale US features in our study show significant difference between the benign and malignant ovarian lesions. From these US features, we concluded that the malignant ovarian lesions show large tumor volume $>890.82 \pm 123.76$, non-hyperechoic solid components, papillary projection, thick internal septa $\geq 3$ $\mathrm{mm}$, and thick wall $\geq 3 \mathrm{~mm}$. The presence of nonhyperechoic solid component followed by papillary projection shows the highest diagnostic performance of the ovarian lesion in comparison to the other US features with $(92.5 \%$ vs $83 \%)$ sensitivity, (97\% vs $93.2 \%)$ specificity, (94.8\% vs $88.4 \%)$ accuracy, and (0.94 vs 0.88 ) AUC, respectively. Also, the non-hyperechoic solid component and papillary projection were the most consistent and

Table 3 Diagnostic performance of pulsatility and resistive indices

\begin{tabular}{lll}
\hline Indices & $\begin{array}{l}\text { Pulsatility } \\
\text { index }\end{array}$ & $\begin{array}{l}\text { Resistive } \\
\text { index }\end{array}$ \\
\hline Sensitivity & $79 \%$ & $79 \%$ \\
Specificity & $84 \%$ & $95 \%$ \\
Positive predictive value & $86 \%$ & $95 \%$ \\
Negative predictive value & $75 \%$ & $78 \%$ \\
Positive likelihood ratio & 5 & 15 \\
Negative likelihood ratio & 0.25 & 0.22 \\
Are under the curve & 0.89 & 0.92 \\
Accuracy & $81 \%$ & $88 \%$ \\
Cutoff point & $<1.6$ & $<0.60$ \\
$p$ value & $<\mathbf{0 . 0 0 1}$ & $<\mathbf{0 . 0 0 1}$ \\
\hline
\end{tabular}

$p$ value was significant if $<0.05$ significant predictors or risk factors for ovarian cancer with 19.45 and 4.56 odds ratio, respectively. These results were concordant with the result of the studies done by Brown et al. [15], Valentin et al. [16], and Herrmann et al. [17], which demonstrated that the non-hyperechoic solid component feature has long been recognized as strongly associated with malignancy in both gross pathologic and sonographic feature. Also, Khurana et al. [10] reported that the papillary projections was a predictor of malignancy.

Timmerman et al.'s [18] and Granberg et al.'s [19] results were agreed with our results in that the presence of thick septation was the significant predictor or risk factor for ovarian cancer as we reported in our study that its odds ratio was 3.45.

In our study, color Doppler allows mapping of the blood flow within the mass and shows neovascularity in $88.7 \%$ of malignant lesions and central blood flow in $73.6 \%$ of these lesions, but $98 \%$ of the benign ovarian lesions show peripheral or absent blood flow; these results correlated well with the study done by Khurana et al. [10] who reported that the detection of the blood flow has consistently related to the malignant ovarian lesions as $97.5 \%$ neovascularity could be seen in the malignant ovarian lesions. Also, our results agreed with the results of the study that was done by Barroilhet et al. [4] who demonstrated that the central blood flow concerning with malignancy and the absence of blood flow or peripheral blood flow almost suggest the benignity and rolled out the malignancy as the central blood flow in their study was identified in $75.9 \%$ of the malignant ovarian lesions. From the logistic regression test, we concluded that the presence of central blood flow was a significant predictor of ovarian cancer with 7.55 odds ratio.

Spectral Doppler can measure the blood flow indices to determine the resistance within the vessels using the RI and PI. The values of RI and PI in our study were lower in malignant lesions $(0.60 \pm 0.18$ and $1.6 \pm 0.51$, respectively) than in benign lesions $(0.89 \pm 0.17$ and 2.54 \pm 1.08 , respectively). These results were in accordance with the data reported by Khurana et al. [10] in which the mean values of RI and PI for malignant lesions were less than for benign lesions. Despite the better diagnostic performance of the RI than PI in our study in discrimination between benign and malignant ovarian lesions, they observed only in $58.5 \%$ and $60.4 \%$ of malignant tumors, respectively. These results show low clinical values of the RI and PI as diagnostic tool used in differentiation between benign and malignant ovarian lesions. Ueland et al. [20] also concluded that the addition of Doppler US did not improve the diagnostic accuracy of ovarian lesions, and reported that the morphological features only are an accurate and inexpensive method used for 
this purpose. From our logistic regression test, we reported that the RI and PI were insignificant predictors. From our results, we reported that the color Doppler flow imaging should be used to evaluate the presence and location of flow in ovarian lesions without a need for RI or PI, as they had no more value than color flow Doppler in addition to its non-feasibility and the timeconsuming [21].

This study has several limitations; firstly, we did not evaluate the CA-125 as a predictor of ovarian malignancy. Secondly, this study was done in ovarian lesions only not in adnexal masses. Thirdly, relatively smaller sample size relative to the previous studies, not being a multicentric study.

\section{Conclusions}

As evident from the above discussion, the golden results of our study is picking up three gray-scale US features as the non-hyperechoic solid component, papillary projection, thick septa, and one Doppler feature which is the central blood flow and one clinical feature which is the old age $\geq 52$ years as predictors or risk factors for ovarian cancer. This diagnostic approach we apply is simple, rapid, and recommend that initial evaluation of the patient age should be done thoroughly, as it is an art that cannot be replaced by sophisticated diagnostic gadget and also concluded that the use of the spectral Doppler parameter as RI and PI has no more value in prediction of ovarian cancer and this will save time and money. In the absence of the above features, the risk of malignancy is low, and conservative management with follow-up scans may be appropriate.

\section{Abbreviations}

US: Ultrasonography; Rl: Resistive index; PI: Pulsatility index; PPV: Positive predictive value; NPV: Negative predictive value; AUC: Area under receiver operating curve

\section{Acknowledgements}

Not applicable.

\section{Authors' contributions}

Corresponding Author: LMRK: Dr. Lamiaa was responsible for the study design, analysis, and interpretation of the data, editing, drafting, and submission of the manuscript. Guarantor of integrity of the entire study. CoAuthors: HHMD: She was responsible for data acquisition and statistical analysis. GSS: She was responsible for the study concept, final approval, and revision of the manuscript before its submission. AS: She was responsible for the data acquisition and analysis, examination, and referral of all the patients to the radiodiagnosis department. MAA: He was responsible for the quality control of data and the accuracy of the references. MTH: She was responsible for revision all the pathological specimen after surgery, and writing the pathological part of the manuscript. All authors have approved the final manuscript.

\section{Funding}

The authors state that this work has not received any funding.

\section{Availability of data and materials}

The datasets used and/or analyzed during the current study are available from the corresponding author on reasonable request.

\section{Ethics approval and consent to participate}

This study was approved by the Research Ethics Committee of the Faculty of Medicine at Assiut University in Egypt in February 28, 2017, and its number is 17100016. Written informed consent was obtained from all patients to participate in this study.

\section{Consent for publication}

All patients included in this research gave written informed consent to publish the data contained within this study.

\section{Competing interests}

The authors of this manuscript declare no relationships with any companies, whose products or services may be related to the subject matter of the article.

\section{Author details}

'Diagnostic Radiology Department, South Egypt Cancer Institute, Assiut University, 8 El Mesak Street Branch of King Seti, Assuit 71111, Egypt. ${ }^{2}$ Diagnostic Radiology Department, Faculty of Medicine, Assiut University, Assuit, Egypt. ${ }^{3}$ Radiation Oncology Department, South Egypt Cancer Institute, Assiut University, Assuit 71111, Egypt. ${ }^{4}$ Medical Oncology and Hematological Malignancy Department, South Egypt Cancer Institute, Assiut University, Assuit 71111, Egypt. ${ }^{5}$ Oncologic Pathology Department, South Egypt Cancer Institute, Assiut University, Assuit 71111, Egypt.

Received: 7 December 2019 Accepted: 17 March 2020

Published online: 23 March 2020

\section{References}

1. Abramowicz JS, Timmerman D (2019) Clinical opinion ovarian massdifferentiating benign from malignant: the value of the International Ovarian Tumor Analysis ultrasound rules. Am J Obstet Gynecol. 217(6):652660

2. Grab D, Flock F, Stöhr I, Nüssle K, Rieber A, Fenchel S et al (2000) Classification of asymptomatic adnexal masses by ultrasound, magnetic resonance imaging, and positron emission tomography. Gynecol Oncol 77(3):454-459

3. Hippisley-Cox JCC (2012) Identifying women with suspected ovarian cancer in primary care: derivation and validation of algorithm. BMJ:344d8009

4. Barroilhet L, Vitonis A, Shipp T, Muto M, Benacerraf B (2012) Sonographic predictors of ovarian malignancy. J Clin Ultrasound. 4:269-274

5. Dharita S, Sandip S, Jay P (2013) Doppler ultrasound: a good and reliable predictor of ovarian malignancy. J Obstet Gynaecol India 63:186-189

6. Harris RD, Javitt MC, Glanc P, Brown DL, Dubinsky T, Harisinghani MG et al (2013) ACR appropriateness criteria ${ }^{\oplus}$ clinically suspected adnexal mass. Ultrasound Quart 29(1):79-86

7. Kinkel K, Hricak H, Lu Y, Tsuda KFR (2000) US characterization of ovarian masses: a meta-analysis. Radiol 217(3):803-811

8. Van Holsbeke C, Van Calster B, Valentin L, Testa AC, Ferrazzi E, Dimou I et al (2007) External validation of mathematical models to distinguish between benign and malignant adnexal tumors: a multicenter study by the International Ovarian Tumor Analysis Group. Clin Cancer Res. 13:4440-4447

9. Khurana I, Satia MN (2016) Preoperative evaluation of ovarian masses with color Doppler and its correlation with pathological finding. Int J Reprod Contracept Obstet Gynecol. 5(7):2084-2092

10. Khalaf LMR, Desoky HHM, Seifeldein GS, El-sharkawy M, Sayed MM, Ahmed S et al (2019) The diagnostic efficacy of Gynecology Imaging Reporting and Data System (GI-RADS): single-center prospective cross-sectional study. EJRNM:50-61

11. Guerriero S, Alcazar JL, Coccia ME et al (2002) Complex pelvic mass as a target of evaluation ofvessel distribution by color Doppler sonography for the diagnosis of adnexal malignancies: results of a multicenter European study. J Ultrasound Med. 21:1105-1111

12. Valentin $L$ (1999) Pattern recognition of pelvic masses by gray-scale ultrasound imaging: the contribution of Doppler ultrasound pattern. Ultrasound Obstet Gynecol 14:338-347

13. Heintz AP, Odicino F, Maisonneuve P et al (2006) Carcinoma of the ovary. FIGO 6th annual report on the results of treatment in gynecological cancer. Int J Gynaecol Obs 95:s161-s192

14. Scully RE, Sobin L (1999) WHO histological classification of ovarian tumors. Heidelb Springer-Verlag, Geneva 
15. Brown DL, Doubilet PM, Miller FH, Frates MC, Laing FC, DiSalvo DN et al (1998) Benign and malignant ovarian masses: selection of the most discriminating gray-scale and Doppler sonographic features. Radiol 208(1): 103-110

16. Valentin L, Sladkevicius PMK (1994) Limited contribution of Doppler velocimetry to the differential diagnosis of extrauterine pelvic tumors Obstet Gynecol 83(3):425-433

17. Herrmann JU, Locher GWGA (1987) Sonographic patterns of ovarian tumors: prediction of malignancy. Obstet Gynecol 69(5):777-781

18. Timmerman D, Van Calster B, Testa AC et al (2010) Ovarian cancer prediction in adnexal masses using ultrasound-based logistic regression models: a temporal and external validation study by the IOTA group. Ultrasound Obs Gynecol. 36:226

19. Granberg S, Wikland MJI (1989) Macroscopic characterization of ovarian tumors and the relation to the histological diagnosis: criteria to be used for ultrasound evaluation. Gynecol Oncol 35(2):139-144

20. Ueland FR, DePriest PD, Pavlik EJ, Kryscio RJ van NJ. (2003) Preoperative differentiation of malignant from benign ovarian tumors: the efficacy of morphology indexing and Doppler flow sonography. Gynecol Oncol. 91:46-50

21. Holalkere N, Katur AM, Lee SI (2009) Issues in imaging malignant neoplasms of the female reproductive system. Curr Probl Diagn Radiol. 38(1):1-16

\section{Publisher's Note}

Springer Nature remains neutral with regard to jurisdictional claims in published maps and institutional affiliations.

\section{Submit your manuscript to a SpringerOpen ${ }^{\circ}$ journal and benefit from:}

- Convenient online submission

- Rigorous peer review

- Open access: articles freely available online

High visibility within the field

- Retaining the copyright to your article

Submit your next manuscript at $\boldsymbol{\nabla}$ springeropen.com 